ORIGINAL ARTICLE

\title{
Responses to a fourth dose of Haemophilus influenzae type $B$ conjugate vaccine in early life
}

\author{
M H Slack, D Schapira, R J Thwaites, M Burrage, J Southern, D Goldblatt, E Miller
}

Arch Dis Child Fetal Neonatal Ed 2004;89:F269-F271. doi: 10.1136/adc.2003.030718

See end of article for authors' affiliations

Correspondence to: Dr Slack, Neonatal Unit, Princess Anne Hospital, Southampton, Hampshire SO32 1GY, UK: marts@doctors.org.uk

Accepted 9 June 2003
Objective: To describe the immune response of preterm infants, with a reduced response to primary Haemophilus influenzae type B (Hib) immunisation, to a fourth dose of Hib conjugate vaccine given in early life.

Design: Prospective observational study.

Setting: Five Wessex Neonatal Units.

Patients: Infants born at $<32$ weeks and immunised with three doses of combined acellular pertussis-Hib vaccine, with a Hib lgG geometric mean concentration $(G M C)<1.0 \mu \mathrm{g} / \mathrm{ml}$ after these primary immunisations.

Interventions: An additional fourth dose of Hib conjugate vaccine given before 1 year of age. Blood taken to assess Hib lgG concentration and avidity after immunisation.

Main outcome measures: Hib lgG GMC and avidity index.

Results: Ninety six infants (mean gestational age at birth 29.1 weeks) received a fourth dose of Hib at a mean age of 7.8 months. Hib lgG GMC after the primary immunisations was $0.17 \mu \mathrm{g} / \mathrm{ml} 195 \%$ confidence interval (Cl) 0.14 to 0.20$)$ rising to $4.68 \mu \mathrm{g} / \mathrm{ml}(95 \% \mathrm{Cl} 3.36$ to 6.57$)$ after the fourth dose $(p<0.0001)$. The lgG response to the fourth dose correlated positively with the response after the primary immunisations ( $p<0.001$ ). Hib lgG geometric mean avidity index (GMAl) after the primary immunisations was $30.87(95 \% \mathrm{Cl} 20.40$ to 46.73$)$. This increased to $124.73(95 \% \mathrm{Cl} 109.93$ to $141.51)$ after the fourth dose $(p<0.0001)$.

Conclusion: Preterm infants with very low $\lg G$ responses to Hib after primary immunisations with a combined acellular pertussis-Hib vaccine mount a good response to a fourth dose of Hib. This study suggests that all infants will benefit from a fourth dose of Hib, regardless of the age at which it is given.
S ince 1998 invasive Haemophilus influenzae type B (Hib) disease in the United Kingdom has been increasing despite high levels of immunisation. This may in part be due to a failure of a large number of infants to achieve protective Hib IgG titres after accelerated immunisation at 2, 3, and 4 months with acellular pertussis containing Hib combination vaccines. ${ }^{1}$ In response, the UK Department of Health has offered all children aged 6 months to 4 years a Hib booster. ${ }^{2}$ There are, however, few data available on the use of an early ( $<1$ year of age) booster dose of Hib in infants with low IgG titres after accelerated primary immunisation and no data generated on Hib boosting when primary immunisation has been given at the same time as a meningococcal serogroup C conjugate vaccine, introduced into the United Kingdom schedule in 1999.

We have previously shown that the IgG response of preterm and term infants to Hib combined with an acellular pertussis vaccine is very low. ${ }^{3}$ In this study we investigate the response of preterm infants with low levels of Hib IgG after primary immunisation to an early fourth dose of Hib. We believe the results provide the evidence base for the recent Hib booster campaign, particularly as the group studied (preterm infants) represents the "worst case scenario" in relation to Hib response.

\section{METHODS}

\section{Subjects and immunisations}

Preterm infants born at less than 32 weeks gestation were recruited from five neonatal units in one UK region. The study had ethical approval from the four local research ethics committees serving the five centres, and informed consent was obtained from the parents before enrolment. All infants received three doses of a combined diphtheria/tetanus/ acellular pertussis (DTaP)-Hib conjugate vaccine (InfanrixHib; GlaxoSmithKline, Uxbridge, Middlesex, UK; $0.5 \mathrm{ml}$ dose containing $30 \mathrm{IU}$ diphtheria toxoid, 40 IU tetanus toxoid, $25 \mu \mathrm{g}$ pertussis toxin, $25 \mu \mathrm{g}$ filamentous haemagglutinin, $8 \mu \mathrm{g}$ pertactin, and $10 \mu \mathrm{g}$ purified capsular polysaccharide of Hib covalently bound to about $30 \mu \mathrm{g}$ tetanus toxoid) and meningococcal serogroup $\mathrm{C}$ conjugate vaccine (Meningitec; Wyeth, Collegeville, Pennsylvania, USA; $0.5 \mathrm{ml}$ dose containing $10 \mu \mathrm{g}$ meningococcal serogroup $\mathrm{C}$ oligosaccharide conjugated to about $15 \mu \mathrm{g} \mathrm{CRM}_{197}$ protein) at 2, 3, and 4 months of age. ${ }^{3}$ Preterm infants with a Hib $\operatorname{IgG}<1.0 \mu \mathrm{g} / \mathrm{ml}$ after the three primary immunisations were offered a fourth dose of Hib conjugate vaccine (Act-HIB; Aventis Pasteur MSD, Lyon, France; $0.5 \mathrm{ml}$ dose containing $10 \mu \mathrm{g}$ purified Hib capsular polysaccharide covalently bound to $24 \mu \mathrm{g}$ tetanus protein).

\section{Assays}

Blood was taken by needle venepuncture into Microtainer Serum Separator tubes four weeks after the additional fourth Hib vaccine was given. Antibody concentrations to Hib were assayed at the Centre for Applied Microbiology and Research (CAMR), Salisbury, Wiltshire, UK by enzyme linked immunosorbent assay using a standardised protocol as previously described. ${ }^{4}$ The lower limit of detection of the assay was $0.15 \mu \mathrm{g} / \mathrm{ml}$. Samples with undetectable Hib IgG were assigned a value of half the lower limit of detection $(0.08 \mu \mathrm{g} / \mathrm{ml})$. Hib IgG avidity was determined by the

Abbreviations: $95 \% \mathrm{Cl}, 95 \%$ confidence intervals; GMAl, geometric mean avidity index; GMC, geometric mean concentration; Hib, Haemophilus influenzae type B 


\begin{tabular}{|c|c|c|c|}
\hline $\begin{array}{l}\text { Response to primary } \\
\text { immunisations }(\mu \mathrm{g} / \mathrm{ml})\end{array}$ & $\begin{array}{l}\text { GMC after primary } \\
\text { immunisations }\end{array}$ & $\begin{array}{l}\text { GMC after } \\
\text { fourth dose }\end{array}$ & $\begin{array}{l}\text { GMAl after } \\
\text { fourth dose }\end{array}$ \\
\hline $\begin{array}{c}<0.15 \\
95 \% \mathrm{Cl} \\
\text { Number } \\
0.15-1.0 \\
95 \% \mathrm{Cl} \\
\text { Number } \\
\text { p Value }\end{array}$ & $\begin{array}{l}0.08 \\
\text { Assigned } \\
51 \\
0.40 \\
0.34 \text { to } 0.46 \\
45 \\
<0.0001\end{array}$ & $\begin{array}{l}2.59 \\
1.64 \text { to } 4.10 \\
51 \\
9.51 \\
6.08 \text { to } 13.76 \\
45 \\
0.0001\end{array}$ & $\begin{array}{l}86.58 \\
68.53 \text { to } 109.40 \\
42 \\
127.00 \\
100.60 \text { to } 160.33 \\
38 \\
0.022\end{array}$ \\
\hline
\end{tabular}

$95 \% \mathrm{Cl}, 95 \%$ confidence interval.

Immunobiology Unit, Institute of Child Health, London, UK as previously described. ${ }^{5}$ Avidity results in this study are multiplied by 100 compared with previous reports for computational ease. Avidity could only be measured where Hib IgG was $>0.5 \mu \mathrm{g} / \mathrm{ml}$. The lower limit of detection of the avidity assay was 50 avidity units. Sera with unrecordable avidity were assigned a value equal to half the lower limit of detection (25 avidity units).

\section{Statistical analysis}

Hib IgG concentrations after the third and fourth doses were $\log _{10}$ transformed to achieve normality. Hib IgG geometric mean concentrations (GMCs) and avidity index (GMAI) were calculated with 95\% confidence intervals (95\% CI) and compared using Student's $t$ test. The effect of patient variables on antibody responses was assessed using linear regression. Variables with $\mathrm{p}<0.2$ were entered into a multivariable regression model.

\section{RESULTS}

A total of 122 preterm infants (mean gestational age at birth 29.1 weeks (range 24.2-31.9); mean birth weight $1266 \mathrm{~g}$ (range 490-2100)) were immunised at 2, 3, and 4 months of age. The Hib IgG response in 105 of these infants after primary immunisations has been reported previously. ${ }^{3}$ The Hib IgG GMC after the primary immunisation for all the preterm infants was $0.29 \mu \mathrm{g} / \mathrm{ml}$. Ninety six $(79 \%)$ had Hib

Table 2 Proportion of infants achieving Hib lgG concentrations $\geqslant 0.15$ and $\geqslant 1.0 \mu \mathrm{g} / \mathrm{ml}$ after primary immunisations and after additional fourth dose of Hib conjugate vaccine

\begin{tabular}{lll}
\hline $\begin{array}{l}\text { Hib } \mathrm{lgG} \\
(\mu \mathrm{g} / \mathrm{ml})\end{array}$ & $\begin{array}{l}\text { After primary } \\
\text { immunisations } \\
(\mathbf{n}=122)\end{array}$ & $\begin{array}{l}\text { After fourth } \\
\text { dose }(\mathbf{n}=96)\end{array}$ \\
\hline$\geqslant 0.15$ & $58 \%$ & $95 \%$ \\
$\geqslant 1.0$ & $21 \%$ & $85 \%$ \\
\hline
\end{tabular}

IgG $<1.0 \mu \mathrm{g} / \mathrm{ml}$ after primary immunisations and received a fourth immunisation; in 51 (42\%) Hib IgG was $<0.15 \mu \mathrm{g} / \mathrm{ml}$ (historical level for short term protection). The mean age at receipt of the additional dose was 7.8 months (range 6.211.5).

In these 96 infants, the Hib IgG GMC after the primary immunisation was $0.17 \mu \mathrm{g} / \mathrm{ml}$ (95\% CI 0.14 to 0.20 ). This rose to $4.68 \mu \mathrm{g} / \mathrm{ml}$ (95\% CI 3.36 to 6.57 ) after the fourth dose $(\mathrm{p}<0.0001)$. Table 1 shows GMCs for infants with Hib IgG concentration $<0.15 \mu \mathrm{g} / \mathrm{ml}$ and $\geqslant 0.15 \mu \mathrm{g} / \mathrm{ml}$ after the primary and booster immunisations. Table 2 shows the proportions of infants achieving Hib IgG concentrations $\geqslant 0.15$ and $1.0 \mu \mathrm{g} / \mathrm{ml}$ after the primary and additional fourth immunisations. Five infants failed to achieve a Hib IgG $\geqslant 0.15 \mu \mathrm{g} / \mathrm{ml}$ after the fourth dose. There was no difference between these infants and those who did achieve concentrations $\geqslant 0.15 \mu \mathrm{g} / \mathrm{ml}$ in mean age at receipt of the fourth dose (8.1 and 7.8 months respectively, $p=0.52$ ).

The effect of a number of patient variables (gestational age at birth, birth weight, age at third dose, Hib IgG after third dose, age at fourth dose, number of doses of antenatal steroids, and number of courses of postnatal steroids) on IgG response to the fourth dose were assessed using linear regression. Variables with $\mathrm{p}<0.2$ in linear regression (age at third dose, $p=0.063$; IgG after third dose, $p<0.001$; age at fourth dose, $\mathrm{p}=0.034$ ) were analysed further using multivariable regression. Table 3 shows the results of the multivariable regression analysis. Of note, IgG response to a fourth dose correlated positively with age at fourth dose in linear regression, but this ceased to be significant when controlled for age at completion of the primary immunisations.

The Hib GMAI was determined after the third dose, and after the fourth dose when given. As the response to the primary immunisations was so low in this group, it was only possible to measure GMAI after the third dose in 11 infants. GMAI after the third dose in infants not requiring an additional dose was also measured. Table 4 shows the results. Table 1 shows Hib GMAIs after the fourth dose for infants with $\mathrm{Hib}$ IgG $<0.15 \mu \mathrm{g} / \mathrm{ml}$ or $\geqslant 0.15 \mu \mathrm{g} / \mathrm{ml}$ after the primary immunisations.

Table 3 Multivariable analysis: influence of age in days at completion of primary immunisations, $\lg G$ response $(\mu \mathrm{g} / \mathrm{ml}$ ) to primary immunisations, and age (days) at receipt of fourth dose on $\lg G$ response to a fourth dose of $\mathrm{Hib}$

\begin{tabular}{llll}
\hline & Age at third dose & lgG after third dose & Age at fourth dose \\
\hline $\begin{array}{l}\text { \% Change in lgG titre per } \\
\text { unit change in variable }\end{array}$ & $+0.1 \%$ & $+71.6 \%$ & $+0.4 \%$ \\
$95 \% \mathrm{Cl}$ & $-0.8 \%$ to $+1.0 \%$ & $+35.2 \%$ to $+100 \%$ & $-0.02 \%$ to $+0.9 \%$ \\
$\mathrm{p} \mathrm{Value}$ & 0.77 & $<0.001$ & 0.061 \\
\hline
\end{tabular}

$95 \% \mathrm{Cl}, 95 \%$ confidence interval. 
Table 4 Hib geometric mean antibody avidities (GMAls) after the third dose of Hib for infants who did not require a fourth dose and after the third and fourth dose for those who did

\begin{tabular}{|c|c|c|}
\hline & $\begin{array}{l}\text { Hib } \lg G>1.0 \mu \mathrm{g} / \mathrm{ml} \\
\text { after primary } \\
\text { immunisations } \\
\text { (no } 4 \text { th dose given) }\end{array}$ & $\begin{array}{l}\text { Hib } \lg G<1.0 \mu \mathrm{g} / \mathrm{m} \mid \\
\text { after primary } \\
\text { immunisations } \\
\text { (4th dose given) }\end{array}$ \\
\hline $\begin{array}{l}\text { Hib GMAl after } \\
\text { 3rd dose }\end{array}$ & 76.87 & 30.87 \\
\hline $95 \% \mathrm{Cl}$ & 67.15 to 88.00 & 20.40 to 46.73 \\
\hline Number & 26 & 11 \\
\hline $\begin{array}{l}\text { Hib GMAl after } \\
\text { 4th dose }\end{array}$ & NA & 103.86 \\
\hline $95 \% \mathrm{Cl}$ & NA & 87.87 to 122.77 \\
\hline Number & NA & \\
\hline $\mathrm{p}$ Value & NA & $<0.0001$ \\
\hline
\end{tabular}

Of those infants who were given an additional dose of Hib, 10 had received at least one course of postnatal steroids for chronic lung disease. The Hib GMC for these infants after the primary immunisations was $0.16 \mu \mathrm{g} / \mathrm{ml}$. This rose to $3.68 \mu \mathrm{g} /$ $\mathrm{ml}$ after the fourth dose $(\mathrm{p}=0.002)$.

\section{DISCUSSION}

We have shown that preterm infants with very low IgG responses to Hib conjugate vaccine mount an adequate response to an early additional fourth dose of Hib. The GMC after the booster, even in infants who were $<0.15 \mu \mathrm{g} / \mathrm{ml}$ after the primary immunisations, compares favourably with the concentrations achieved after the three dose primary course in term infants receiving a separate Hib vaccine at 2/3/4 months (Hib IgG GMC $4.50 \mu \mathrm{g} / \mathrm{ml}, 95 \%$ CI 3.21 to 6.32). ${ }^{6}$ These findings, in preterm infants with IgG concentrations after the primary immunisations lower than those of term infants ${ }^{3}$ indicate that good responses can be expected in term infants boosted soon after primary immunisation, as occurred recently in the United Kingdom.

We are unable to say with certainty whether the response to the additional dose represents a primary or a memory response, as there are no comparable data on the response expected in naïve and primed infants to a booster dose given at this early age. However, as the GMAI after the booster was higher in the group with Hib IgG concentrations $\geqslant 0.15 \mu \mathrm{g} /$ $\mathrm{ml}$ after the primary immunisations than in those with concentrations of $<0.15 \mu \mathrm{g} / \mathrm{ml}$, this suggests some degree of memory in the former group. The GMAI after the booster in those with concentrations $<0.15 \mu \mathrm{g} / \mathrm{ml}$ was similar to that seen in the 26 infants with concentrations $>1.0 \mu \mathrm{g} / \mathrm{ml}$, suggesting a primary rather than a memory response.

This study strongly suggests that all infants will benefit from an additional fourth Hib dose, irrespective of the timing of its delivery or the antibody concentrations achieved after the third dose. For children in whom the fourth dose may be a priming rather than a boosting dose, there is the question of whether a subsequent booster would be needed. We intend to follow up this cohort of preterm infants to compare antibody persistence in those for whom the fourth dose was acting as a booster compared with those in whom it was probably a priming immunisation.

\section{ACKNOWLEDGEMENTS}

We express our gratitude to the parents and infants who participated in the study, to study nurses Mrs C Schapira, Mrs T Griffen, Mrs J Hovey, Mrs D Hughes-Thomas, and Mrs C Moore, and to all the consultants in the participating centres for allowing us to investigate their patients. Nick Andrews (PHLS) offered invaluable statistical advice for which we are extremely grateful.

\section{Authors' affiliations}

M H Slack, R J Thwaites, Department of Paediatrics, St Mary's Hospital, Portsmouth, Hampshire, UK

D Schapira, Department of Paediatrics, Royal Hampshire County Hospital, Winchester, Hampshire, UK

M Burrage, Centre for Applied Microbiology and Research, Salisbury, Wilts, UK

J Southern, E Miller, Immunisation Division, Communicable Disease Surveillance Centre, Public Health Laboratory Service, London, UK D Goldblatt, Immunobiology Unit, Institute of Child Health, London

Financial support: Department of Health; Meningitis Research Foundation

\section{REFERENCES}

1 Steinhoff M, Goldblatt D. Conjugate Hib vaccines. Lancet 2003;361:360-1.

2 Joint Committee on Vaccination and Immunisation. Draft Minutes of the Meeting of the Joint Committee on Vaccination and Immunisation held on 01 / 11/02. www.doh.gov.uk/icvi/mins01 nov02.htm.

3 Slack MH, Schapira D, Thwaites RJ, et al. Immune response of preterm infants to meningococcal serogroup $C$ and combined diphtheria-tetanus toxoidsacellular pertussis-Haemophilus influenzae type b conjugate vaccines. J Infect Dis 2001;184:1617-20.

4 Goldblatt D, Richmond P, Millard E, et al. The induction of immunologic memory after vaccination with Haemophilus influenzae type $b$ conjugate and acellular pertussis-containing diphtheria, tetanus, and pertussis combination. $J$ Infect Dis 1999;180:538-41.

5 Goldblatt D, Pinto Vaz ARJPM, Miller E. Antibody avidity as a surrogate marker of successful priming by Haemophilus influenzae type $b$ conjugate vaccines following infant immunization. J Infect Dis 1998;177:1112-15.

6 Begg NT, Miller E, Fairley CK, et al. Antibody responses and symptoms after DTP and either tetanus or diphtheria Haemophilus influenzae type B conjugate vaccine given for primary immunisation by separate or mixed injection. Vaccine 1995; 13:1547-50. 